\title{
Ionic liquids as entrainers for terpenes fractionation and other relevant separation problems
}

\author{
Sérgio M. Vilas-Boas ${ }^{\text {a,b }}$, Gabriel Teixeira ${ }^{\mathrm{a}, \mathrm{c}}$, Sabrina Rosini ${ }^{\mathrm{a}, \mathrm{c}}$, Mónia A.R. Martins ${ }^{\mathrm{b}}$, Priscilla S. Gaschi ${ }^{\mathrm{c}}$, \\ João A.P. Coutinho ${ }^{\mathrm{b}}$, Olga Ferreira ${ }^{\mathrm{a}}$, Simão P. Pinho ${ }^{\mathrm{a}, *}$ \\ a Centro de Investigação de Montanha (CIMO), Instituto Politécnico de Bragança, Campus de Santa Apolónia, 5300-253 Bragança, Portugal \\ b CICECO - Aveiro Institute of Materials, Department of Chemistry, University of Aveiro, 3810-193 Aveiro, Portugal \\ c UTFPR - Departamento de Engenharia Química, Universidade Tecnológica Federal do Paraná, 84016-210 Ponta Grossa, Brazil
}

\section{A R T I C L E I N F O}

\section{Article history:}

Received 24 July 2020

Received in revised form 22 September 2020

Accepted 20 October 2020

Available online 27 October 2020

\section{Keywords:}

Ionic liquid

Activity coefficient at infinite dilution

Deterpenation

Desulfurization

COSMO-RS

\begin{abstract}
A B S T R A C T
This work discusses the potential of two phosphonium-based ionic liquids (ILs), $\left[\mathrm{P}_{6,6,6,14}\right] \mathrm{Cl}$ and $\left[\mathrm{P}_{6,6,6,14}\right]\left[\left(\mathrm{C}_{8} \mathrm{H}_{17}\right)_{2}\right.$ $\left.\mathrm{PO}_{2}\right]$, and one methylimidazolium-based IL, $\left[\mathrm{C}_{4} \mathrm{mim}\right][\mathrm{OAc}]$, as entrainers in the fractionation of terpene mixtures, in the desulfurization and denitrification of fuel oils, and in the separation of aromatics from aliphatic hydrocarbons. To this aim, the activity coefficients at infinite dilution of 45 solutes were obtained by gas-chromatography in the temperature range (333.15-458.15) K. Selectivities and capacities were calculated showing that $\left[\mathrm{P}_{6,6,6,14}\right] \mathrm{Cl}$ is adequate for the fractionation of $(-)$-menthone/L- $(-)$-menthol mixture, being also a suitable option for the deterpenation of citrus essential oil, and the removal of thiophene and pyridine from aliphatic hydrocarbons. To complement the experimental measurements COSMO-RS model was tested, demonstrating good potential to screen separation agents and give insights for several important separation problems, including the removal of contaminants from fuels and the isolation, fractionation and purification of terpenes mixtures.
\end{abstract}

(c) 2020 Elsevier B.V. All rights reserved.

\section{Introduction}

Ionic liquids (ILs) are complex organic salts, usually presenting melting temperatures inferior to $100^{\circ} \mathrm{C}[1,2]$. Frequently composed by longchain cations coupled with an organic or an inorganic anion, ILs exhibit unique properties including low volatility, good thermal stability and excellent solvation capability [3,4]. Among the remarkable outcomes achieved in several areas, ionic liquids have been explored as replacements of traditional organic solvents in different extraction and purification processes [3,5-8]. Thus, the knowledge of the thermodynamic properties and phase equilibria that describe the affinity between the ionic liquids and the target solutes is essential [9]. The measurement of complete phase diagrams in terms of temperature, pressure and composition is very time-consuming, while other properties such as the activity coefficients at infinite dilution can be used to screen the potential of ILs as mass separation agents, allowing to calculate parameters such as selectivity, capacity and partition coefficients, quite fundamental to design a separation process $[9,10]$. Within the ILs field, this technique was mostly applied to study their interaction with common organic compounds relevant in the chemical industry and refineries and, less frequently, with terpenes and their oxygenated derivatives (terpenoids). The latter are the main components of essential oils (EOs)

\footnotetext{
* Corresponding author.

E-mail address: spinho@ipb.pt (S.P. Pinho).
}

which are volatile, natural, and complex mixtures that can be extracted from flowers, leaves, stems, seeds, and fruits [11,12]. Due to their particular pleasant aromas and bioactivities (antioxidant, antiseptic, and anticarcinogenic), essential oils, and many of their constituents, find application in the food $[13,14]$ cosmetic $[15,16]$ and pharmaceutical [17-19] industries. Terpenoids are the main responsible for the aroma and antioxidant properties of EOs, while terpenes contribute little to the aroma, being easily oxidized and producing off-flavors that deteriorate the quality of the of EOs [20,21]. The removal of terpenes from the oxygenated rich part, process known as deterpenation, is crucial to improve the stability, solubility and storage requirements of commercial EOs $[22,23]$.

The most common separation techniques employed in the deterpenation process are liquid-liquid extraction, vacuum distillation, supercritical fluid extraction, and membrane separation [20]. For industrial purposes, the liquid-liquid extraction is often desirable, since it can be carried out at mild conditions, avoiding the deterioration of the final product [14,24]. Traditionally, this technique is performed using conventional volatile organic solvents, such as methanol, hexane, acetone, ethyl acetate and petroleum ether derivatives [20]. However, alternative neoteric solvents such as hydroalcoholic solvents [25-31], deep eutectic solvents [22,32], or ionic liquids [33-38] are being studied as potential replacements, aiming at better separation performances.

In previous works from our group, methylimidazolium-based ionic liquids were investigated as separation agents in the removal of 
contaminants from aliphatic hydrocarbons [39], and in the fractionation of terpene/terpenoid mixtures [40]. This last work suggested that ILs containing the trihexyl(tetradecyl)phosphonium $\left(\left[\mathrm{P}_{6,6,6,14}\right]\right)$ cation combined with bis(2,4,4-trimethylpentyl)phosphinate $\left.\left[\left(\mathrm{C}_{8} \mathrm{H}_{17}\right)_{2} \mathrm{PO}_{2}\right]\right)$ or acetate [OAc] anions, were suitable for the fractionation of terpene mixtures. Besides, Lago et al. [38] proposed 1-butyl-3-methylimidazolium acetate ([ $\left.\left.\mathrm{C}_{4} \mathrm{mim}\right][\mathrm{OAc}]\right)$ for the deterpenation of citrus essential oil constituted mainly by limonene and linalool.

In this work, experimental measurements of the activity coefficients at infinite dilution and gas-liquid partition coefficients of water and 44 organic solutes (including aliphatic and aromatic hydrocarbons, esters, ethers, ketones, acetonitrile, pyridine, thiophene, alcohols, terpenes, and terpenoids) in three ionic liquids, namely trihexyl(tetradecyl)phosphonium chloride, trihexyl(tetradecyl)phosphonium bis(2,4,4trimethylpentyl)phosphinate and 1-butyl-3-methylimidazolium acetate, were performed by gas chromatography in the temperature range (333.15-458.15) K. The efficiency of the ionic liquids in specific terpene/terpenoid, thiophene/alkane, and aromatic/aliphatic hydrocarbon mixtures was evaluated in terms of the selectivities and capacities, and compared with the data available in the literature for other phosphonium and imidazolium-based ionic liquids.

The use of predictive tools to estimate thermodynamic properties, such as activity coefficient at infinite dilution, is welcome in the screening of potential entrainers for separation processes, since it would reduce the amount of costly and time-consuming experimental measurements [41]. From the available options, the Conductor-like Screening Model for Real Solvents (COSMO-RS) was selected, as it has been successfully applied in the description of thermophysical data of fluids, including selectivities and capacities of relevant industrial problems [40,42-48]. Therefore, selectivities and capacities at infinite dilution predicted by the model were critically compared with the available experimental data.

\section{Experimental}

\subsection{Materials}

The chemical structure, supplier, molar mass, melting temperature and purity of the ionic liquids are presented in Table 1 . Similar information for the organic solutes is presented in Table S1 of Supporting Information (SI). Before being used, all ionic liquids were dried under vacuum (at $1 \mathrm{~Pa}$ and $298.15 \mathrm{~K}$ ), under continuous stirring, for at least $48 \mathrm{~h}$. The organic solutes were used as received from the suppliers.

\section{Methods}

\subsection{Chromatographic measurements}

The retention times were measured using a Varian 3380 gas chromatograph (GC) equipped with a 1041 on-column injector and a thermal conductivity detector (TCD). The procedure for the column preparation and packing follows that described in previous works $[39,40]$. First, the stationary phase was prepared by mixing between $50 \%$ to $55 \%$ in mass of Chromosorb W/AW - DMCS (100-120 mesh) with the ionic liquid. A uniform coating of the Chromosorb with the IL was achieved by dissolving the mixture in methanol under continuous stirring, followed by the evaporation of the solvent until the original mass of the mixture was recovered (uncertainties within $\pm 1 \times 10^{-4} \mathrm{~g}$ ). After, an in-house glass column ( $4 \mathrm{~mm}$ of internal diameter and $1 \mathrm{~m}$ of length) was filled with the stationary phase, and then placed in the GC oven. Before starting the experiments, the columns were pre-conditioned, passing the carrier gas (helium) through the column for, at least, $6 \mathrm{~h}$, at $393.15 \mathrm{~K}$, to ensure complete removal of possible contaminants.

The inlet pressure was registered by a Swagelok $S$ model pressure transducer with an accuracy of $0.25 \%$ BFSL, whereas the atmospheric pressure, the outlet temperature and the exit flow rate were measured by an Agilent (model 5067-0223) Precision Gas Flow Meter. During the experiments with terpenes and terpenoids, the injector and the detector were kept at 553.15 and $573.15 \mathrm{~K}$, respectively. For the other solutes, the temperatures of the injector and detector were set at 473.15 and $523.15 \mathrm{~K}$, respectively. The injector and the detector were kept at the setpoint temperatures for a minimum of 30 min before starting the measurements. The temperature, pressure and flow rate uncertainties are $0.1 \mathrm{~K}, 0.05 \mathrm{~atm}$ and $0.6 \%$, respectively. To achieve an infinite dilution state, the volume of injected solute varied from 0.2 to $0.4 \mu \mathrm{L}$. The experiments were performed, at least, at four different temperatures in a range between $333.15-453.15 \mathrm{~K}$. For a representative set of solutes (minimum 10 solutes, for each IL, including compounds from different families), the activity coefficients at infinite dilution were measured in two independent columns at three different temperatures, presenting an average coefficient of variation of $2 \%$ for $\left[\mathrm{P}_{6,6,6,14}\right] \mathrm{Cl}, 2 \%$ for $\left[\mathrm{P}_{6,6,6,14}\right]$ $\left[\left(\mathrm{C}_{8} \mathrm{H}_{17}\right)_{2} \mathrm{PO}_{2}\right]$ and $4 \%$ for $\left[\mathrm{C}_{4} \mathrm{mim}\right][\mathrm{OAc}]$. Besides, each experiment was repeated twice to check the reproducibility of the results. The thermodynamic information (vapor pressure, density, critical properties, acentric factor, and dipole moment) of terpenes and terpenoids needed to calculate the activity and partition coefficients is available in section S1 of SI (Table S2 and Table S3), whereas these properties were obtained from DIPPR 801 database [50] for all the other organic solutes and water.

\subsection{Density measurements}

Density measurements of pure $\left[\mathrm{P}_{6,6,6,14}\right] \mathrm{Cl}$ and $\left[\mathrm{P}_{6,6,6,14}\right]\left[\left(\mathrm{C}_{8} \mathrm{H}_{17}\right)_{2}\right.$ $\mathrm{PO}_{2}$ ] were performed in an automated SVM 3000 Anton Paar rotational Stabinger viscometer-densimeter in the temperature range between (278.15-373.15) K, at atmospheric pressure. The uncertainty in temperature is $\pm 0.02 \mathrm{~K}$ and the absolute uncertainty in density is $\pm 5 \times 10^{-4} \mathrm{~g} \cdot \mathrm{cm}^{-3}$.

\subsection{Thermodynamic framework}

\subsubsection{Activity coefficients at infinite dilution}

The experimental methodology used in this work is based on methodologies developed independently by Everett [51] and Cruickshank [52], where retention times obtained by GC measurements are used to calculate the activity coefficients at infinite dilution. Assuming that the solute injected is 1 , the carrier gas is 2 , and the non-volatile solvent (IL) in the stationary phase is 3 , the solute activity coefficient at infinite dilution in the IL $\left(\gamma_{13}^{\infty}\right)$ is given by:

$\ln \gamma_{13}^{\infty}=\ln \left(\frac{n_{3} R T}{V_{N} p_{1}^{*}}\right)-\frac{p_{1}^{*}\left(B_{11}-V_{1}^{*}\right)}{R T}+\frac{p_{0} J_{2}^{3}\left(2 B_{12}-V_{1}^{\infty}\right)}{R T}$

where $n_{3}$ is the number of moles of the ionic liquid packed in the column, $R$ is the ideal gas constant, $T$ is the absolute temperature of the column (regulated by the GC oven), $V_{N}$ is the net retention volume of the solute, $p_{1}^{*}$ is the saturated vapor pressure of the solute at the column temperature, $B_{11}$ is the second virial coefficient of the pure solute, $V_{1}^{*}$ is the molar volume of the pure solute, $p_{0}$ is the outlet column pressure, $J_{2}^{3}$ is the pressure correction term, $B_{12}$ is the second virial coefficient of the solute in the carrier gas and $V_{1}^{\infty}$ is the partial molar volume of the solute at infinite dilution. From all the variables of Eq. (1), $J_{2}^{3}$ and $V_{N}$ require further clarification. As discussed in detail by Everett [51] and Blumberg [53], the pressure correction factor is calculated by:

$J_{2}^{3}=\frac{2\left(\frac{p_{i}}{p_{0}}\right)^{3}-1}{3\left(\frac{p_{i}}{p_{0}}\right)^{2}-1}$

where $p_{i}$ is the inlet pressure of the column. The net retention volume, which represents the total volume the solute passes inside the column, is calculated by the following equation: 
Table 1

Chemical structure, name, supplier, melting temperatures $(\mathrm{K})$ and purity (mass fraction) of the studied ionic liquids.

\begin{tabular}{|c|c|c|c|c|c|c|}
\hline Chemical structure cation & Anion & Chemical name and abbreviation & Supplier & $\begin{array}{l}\text { Molar } \\
\text { mass }\end{array}$ & $\begin{array}{l}\text { Melting } \\
\text { temperature } \\
(\mathrm{K})^{\mathrm{a}}\end{array}$ & $\begin{array}{l}\text { Mass } \\
\text { fraction } \\
\text { purity }\end{array}$ \\
\hline & $\mathrm{Cl}^{-}$ & trihexyl(tetradecyl)phosphonium chloride $-\left[\mathrm{P}_{6,6,6,14}\right] \mathrm{Cl}$ & Cytec & 519.31 & $\begin{array}{l}207 \pm 1 \\
{[49]}\end{array}$ & $\geq 0.93^{b}$ \\
\hline & & $\begin{array}{l}\text { trihexyl(tetradecyl)phosphonium bis(2,4,4-trimethylpentyl) } \\
\text { phosphinate - }\left[\mathrm{P}_{6,6,6,14}\right]\left[\left(\mathrm{C}_{8} \mathrm{H}_{17}\right)_{2} \mathrm{PO}_{2}\right]\end{array}$ & Cytec & 773.27 & $N A^{c}$ & $\geq 0.93^{\mathrm{b}}$ \\
\hline & & 1-butyl-3-methyl imidazolium acetate & Iolitec & 198.26 & $\begin{array}{l}210 \pm 1 \\
{[49]}\end{array}$ & $\geq 0.97$ \\
\hline
\end{tabular}

a Values taken from literature.

b Before being used, the ionic liquid was washed with distilled water several times to remove the hydrophilic contaminants and then placed into a vacuum chamber for several days to remove any additional impurities.

c Not available.

$V_{N}=\left(J_{2}^{3}\right)^{-1} U_{0}\left(t_{r}-t_{g}\right)$

where $t_{r}$ and $t_{g}$ are the measured retention times of the solute, and a reference substance not retained by the stationary phase (usually air injected at the same time as the solute) and $U_{0}$ is the outlet volumetric flow rate (at column temperature). Once the flow rate is measured after the carrier gas leaves the detector, $U_{0}$ needs to be corrected by Eq. (4):

$U_{0}=U_{f} \frac{p_{f}}{p_{0}} \frac{T}{T_{f}}$

in which $U_{f}, p_{F}$ and $T_{f}$ are, respectively, the volumetric flow, the pressure and the temperature, measured by the flowmeter. From all the variables of Eq. (1), the thermophysical properties of terpenes and terpenoids ( $p_{1}^{*}$ and $V_{1}^{*}$ ) were calculated using coefficients fitted with experimental data available in the literature. The second order virial coefficients of these solutes were estimated by the method proposed by Tsnonopoulos [54], which requires the knowledge of the dipole moments, estimated using TURBOMOLE 6.1 program package applying the B-P86 density functional theory level with valence triplezeta polarization (TZVP) basis set A complete overview of the properties used in the calculations of $\gamma_{13}^{\infty}$ for terpenes and terpenoids is presented in Table S2 and Table S3. For all the other solutes (aliphatic and aromatic hydrocarbons, ethers, esters, ketones, alcohols, thiophene, acetonitrile, pyridine and water), the same information was compiled from DIPPR 801 [50]. For all the solutes, the mixed second virial coefficient of the solute and the carrier gas $\left(B_{12}\right)$ were estimated by the approach proposed by Tsnonopoulos [55] and discussed, in detail, by Poling et al. [56].

\subsubsection{Excess partial molar properties at infinite dilution}

The knowledge of $\gamma_{13}^{\infty}$ at different temperatures allows the calculation of excess partial molar properties, namely excess enthalpy $\left(\bar{H}_{m}^{E}\right)$, excess Gibbs energy $\left(\bar{G}_{m}^{E}\right)$ and excess entropy $\left(\bar{S}_{m}^{E}\right)$. Using the linear dependence of $\gamma_{13}^{\infty}$ with temperature (van't Hoff plot) and the chemical potential principle for an ideal solution, $\bar{H}_{m}^{E}, \bar{S}_{m}^{E}$ and $\bar{G}_{m}^{E}$ are obtained as follows:

$\ln \gamma_{13}^{\infty}=\frac{\bar{H}_{m}^{E, \infty}}{R} \frac{1}{T}+\frac{\bar{S}_{m}^{E, \infty}}{R}$

$\bar{G}_{m}^{E, \infty}=R T \ln \gamma_{13}^{\infty}$

\subsection{Gas-liquid partition coefficients}

The gas-liquid partition coefficient $\left(K_{L}\right)$ for a solute partitioning between the liquid phase (IL) and a carrier gas is a relevant property to describe the feasibility of a solvent in an extraction process. Similarly to the activity coefficients, the gas-liquid partition can be determined from the same GC experiments according to: [57].

$\ln \left(K_{L}\right)=\frac{c_{1}^{3}}{c_{1}^{2}}=\ln \left(\frac{V_{N} \rho_{3}}{m_{3}}\right)-\frac{P_{0} J_{2}^{3}\left(2 B_{12}-V_{1}^{\infty}\right)}{R T}$

in which $c$ is the molar concentration of the solute, $\rho_{3}$ is the density of the IL and $m_{3}$ is the mass of the IL in the column.

\subsection{Selectivities and capacities}

The performance of an entrainer in a separation problem can be easily assessed from selectivity $\left(S_{i j}^{\infty}\right)$ and capacity $\left(k_{j}^{\infty}\right)$ values, which are directly obtained from the activity coefficients at infinite dilution $\left(\gamma_{13}^{\infty}\right)$ using the following equations:

$S_{i j}^{\infty}=\frac{\gamma_{i 3}^{\infty}}{\gamma_{j 3}^{\infty}}$ 
$k_{j}^{\infty}=\frac{1}{\gamma_{j 3}^{\infty}}$

where the subscripts $i$ and $j$ represent the solutes, being $j$ the solute with the lower activity coefficient value for a given separation, and 3 refers to the ionic liquid.

\subsection{COSMO-RS predictions}

The COSMO-RS method combines a quantum chemistry characterization of the solute and solvent molecules with the statistical thermodynamics description of the surface interactions, being a powerful tool to predict the thermodynamic properties of liquid mixtures $[58,59]$. A full description of the model theoretical basis is found elsewhere [60-63]. In brief, the model requires only the structure, electronic energy and polarization charge density $(\sigma)$ of each component, and from this information, COSMO-RS analyzes the interactions between the segments of each molecule in the mixture to predict the chemical potentials of the compounds. Since the activity coefficients are directly obtained from the chemical potential [63], COSMO-RS has been widely employed to estimate $\gamma_{13}^{\infty}$ data for water and organic solutes in liquid solvents, including ionic liquids.

The first calculation step aims to obtain the energetically optimal state of each compound, which includes its electronic energy and $\sigma$-profiles. To do so, the software TmoleX was employed [64], in which a def-TZVP basis set was applied along with the density theory level (utilizing the B-P86 functional level of theory and the COSMO solvation model). Then, the files generated by Tmolex were inputted in the software COSMOtherm $[65,66]$, where the COSMO-RS predictions were carried out using the BP_TZVP_C30_1701.ctd parametrization. The ionic liquids were described as an equimolar and electroneutral mixture, and the activity coefficients at infinite dilution were corrected from the hypothetically ternary mixture (solute + cation + anion) to the real binary mixture (solute + ionic liquid).

\section{Results and discussion}

\subsection{Activity coefficients at infinite dilution}

The activity coefficients at infinite dilution measured in this work at temperatures between 333.15-453.15 K are listed in Table S4 of SI. Different temperature conditions were selected for the GC measurements depending on the solute/solvent combination, as discussed in detail in Section S2 of Supporting Information.

The activity coefficients in $\left[\mathrm{C}_{4} \mathrm{mim}\right][\mathrm{OAc}]$ are generally higher than in $\left[\mathrm{P}_{6,6,6,14}\right] \mathrm{Cl}$ or $\left[\mathrm{P}_{6,6,6,14}\right]\left[\left(\mathrm{C}_{8} \mathrm{H}_{17}\right)_{2} \mathrm{PO}_{2}\right]$, especially for the less polar solutes. Additionally, in $\left[\mathrm{C}_{4} \mathrm{mim}\right][\mathrm{OAc}]$ and $\left[\mathrm{P}_{6,6,6,14}\right] \mathrm{Cl}, \gamma_{13}^{\infty}$ decreases as the temperature increases for low polar solvents such as alkanes, cycloalkanes, and terpenes. The opposite trend is observed for alcohols and terpenoids (excepting eucalyptol in $\left.\left[\mathrm{C}_{4} \mathrm{mim}\right][\mathrm{OAc}]\right)$. In both ionic liquids, the tendencies are less pronounced for solutes presenting intermediate polarities, such as ethers, esters, and ketones. Regarding $\left[\mathrm{P}_{6,6,6,14}\right]\left[\left(\mathrm{C}_{8} \mathrm{H}_{17}\right)_{2} \mathrm{PO}_{2}\right]$, for most solutes the $\gamma_{13}^{\infty}$ do not present systematic trends with the temperature, excepting alcohols $\left(\gamma_{13}^{\infty}\right.$ increases as $T$ increases), or esters, ketones, 1,4-dioxane, acetonitrile, and pyridine ( $\gamma_{13}^{\infty}$ decreases as $T$ increases). Moreover, all the activity coefficients at infinite dilution in $\left[\mathrm{P}_{6,6,6,14}\right]\left[\left(\mathrm{C}_{8} \mathrm{H}_{17}\right)_{2} \mathrm{PO}_{2}\right]$ are lower than 1 .

Fig. 1 explores the experimental activity coefficients of several solutes in the three ILs at the same temperature, $383.15 \mathrm{~K}$. The data obtained for low volatile terpenoids in $\left[\mathrm{P}_{6,6,6,14}\right] \mathrm{Cl}$ were not included in Fig. 1 as they were measured at much higher temperatures, and no data were obtained for the other two ILs.

In general, the activity coefficients increase as the number of carbons in the chemical structure increases, for a given family, and the tendency

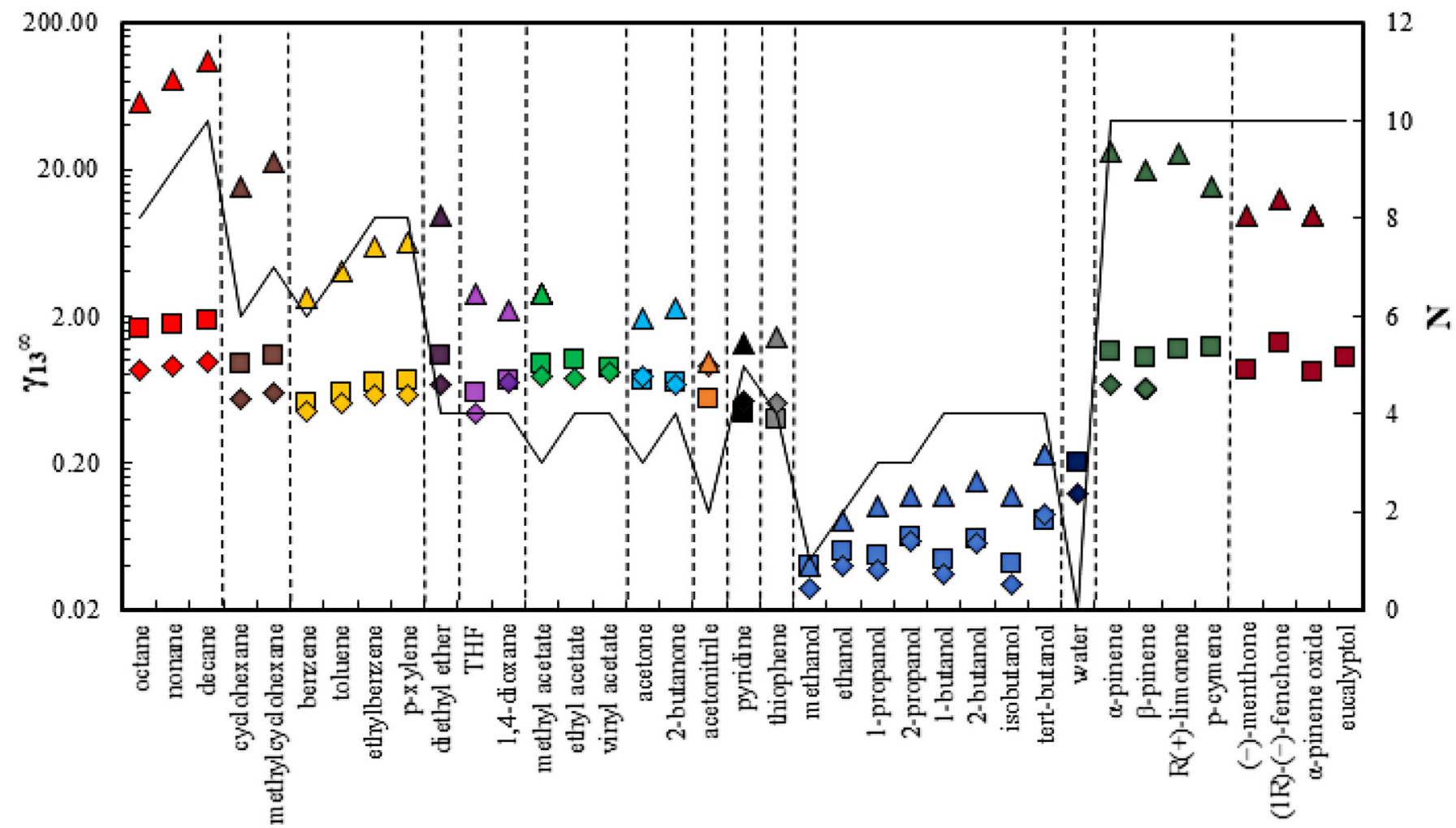

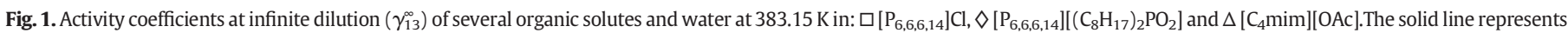
the number of carbons $(\mathrm{N})$ in the solute structure, whereas the dotted lines identify different organic families. 
is more pronounced in the high polar $\left[\mathrm{C}_{4} \mathrm{mim}\right][\mathrm{OAc}]$. For alkanes, cycloalkanes, aromatic hydrocarbons and terpenes, the activity coefficients at infinite dilution follow the order: $\left[\mathrm{C}_{4} \mathrm{mim}\right][\mathrm{OAc}]>\left[\mathrm{P}_{6,6,6,14}\right]$ $\mathrm{Cl}>\left[\mathrm{P}_{6,6,6,14}\right]\left[\left(\mathrm{C}_{8} \mathrm{H}_{17}\right)_{2} \mathrm{PO}_{2}\right]$. For $\left[\mathrm{C}_{4} \mathrm{mim}\right][\mathrm{OAc}]$, there is always a positive deviation from ideality, indicating weak solute/IL interactions in the studied temperature range [67]. This behavior is supported by the highly polar nature of the acetate anion, with a moderate apolar hydrocarbon moiety in the imidazolium ring. The same set of solutes present $\gamma_{13}^{\infty}$ values much closer to the unity in $\left[\mathrm{P}_{6,6,6,14}\right] \mathrm{Cl}$ or $\left[\mathrm{P}_{6,6,6,14}\right]\left[\left(\mathrm{C}_{8} \mathrm{H}_{17}\right)_{2}\right.$ $\left.\mathrm{PO}_{2}\right]$. For both, the long carbon chains present in the cation $\left[\mathrm{P}_{6,6,6,14}\right]^{+}$ are extensive non-polar domains increasing the magnitude of the van der Waals interactions between the solutes and the ionic liquid leading, in some cases, to behaviors close to ideal. A similar outcome is observed comparing the anion effect in the activity coefficients of hydrocarbons in $\left[\mathrm{P}_{6,6,6,14}\right] \mathrm{Cl}$ or $\left[\mathrm{P}_{6,6,6,14}\right]\left[\left(\mathrm{C}_{8} \mathrm{H}_{17}\right)_{2} \mathrm{PO}_{2}\right]$, since dispersion forces in bis (2,4,4-trimethylpentyl)phosphinate $\left(\left[\left(\mathrm{C}_{8} \mathrm{H}_{17}\right)_{2} \mathrm{PO}_{2}\right]^{-}\right)$are stronger than with the chloride anion.

For alcohols, the general trend follows the same order observed for the hydrocarbons, but it presents $\gamma_{13}^{\infty}$ values much lower than aliphatic or aromatic hydrocarbons. In fact, all alcohols present activity coefficients considerably lower than 1 , indicating very strong interactions between the solutes and the ionic liquids, which can be attributed mainly to hydrogen bonding.

To the best of our knowledge, experimental $\gamma_{13}^{\infty}$ values of various solutes in the studied ILs are reported for the first time, including terpenes, terpenoids, esters, ketones, acetonitrile, pyridine, thiophene, and water. For some alkanes, aromatics and alcohols, the $\gamma_{13}^{\infty}$ obtained in this work were compared with the scarce data available in the literature. Globally, a very satisfactory agreement between our data and those previously published was found, giving excellent indications about the consistency of the data measured in this work. This analysis is presented in Fig. S1 and discussed in more detail in Section S2 of SI.

\subsection{Gas-liquid partition coefficients}

The ILs density is needed to calculate the partition coefficients, and the data obtained in this work are also discussed in detail in Section S2 of SI, where Fig. S2 and Table S5 show an extensive comparison to the literature data. For $\left[\mathrm{C}_{4} \mathrm{mim}\right][\mathrm{OAc}]$, the data reported by Almeida et al. [68] were used, while for $\left[\mathrm{P}_{6,6,6,14}\right] \mathrm{Cl}$ and $\left[\mathrm{P}_{6,6,6,14}\right]$ $\left[\left(\mathrm{C}_{8} \mathrm{H}_{17}\right)_{2} \mathrm{PO}_{2}\right]$ the data measured in this work, and presented in Table S6 of SI, were employed.

The gas-liquid partition coefficients obtained in this work are presented in Table S7 of the Supporting Information. This property provides insights on the suitability of the ionic liquid for industrial separation processes, e.g. a liquid-liquid extraction followed by evaporation of the solutes at low pressures. Regarding the essential oils, $K_{L}$ is a useful tool to evaluate the use of ionic liquids in the fractionation of the terpenes mixtures, followed by the recovery and purification of the final product [40].

For all the studied solutes, a temperature increment leads to lower $K_{L}$ values, and consequently, lower concentrations in the liquid phase. To better understand the relationship of this parameter with the structure and functionality of the solutes, Fig. 2 shows the $K_{L}$ values measured at $383.15 \mathrm{~K}$.

The gas-liquid partition coefficients increase with the alkyl-chain in aromatic or aliphatic hydrocarbons, ketones, or esters. In fact, low temperatures and large alkyl chains in the solutes contribute to enhance the solute-IL interactions, especially for the less polar $\left[\mathrm{P}_{6,6,6,14}\right] \mathrm{Cl}$ and $\left[\mathrm{P}_{6,6,6,14}\right]\left[\left(\mathrm{C}_{8} \mathrm{H}_{17}\right)_{2} \mathrm{PO}_{2}\right]$. Fig. 2 also informs that partition coefficients of aliphatic hydrocarbons, terpenes, and thiophene in $\left[\mathrm{C}_{4} \mathrm{mim}\right][\mathrm{OAc}]$ are considerably lower than in the other two ionic liquids. This behavior is due to the poor affinity between the highly polar $\left[\mathrm{C}_{4} \mathrm{mim}\right][\mathrm{OAc}]$ and low polar solutes. Nevertheless, [ $\mathrm{C}_{4}$ mim] [OAc] shows the highest $K_{L}$ values for alcohols, most probably due to the formation of hydrogen

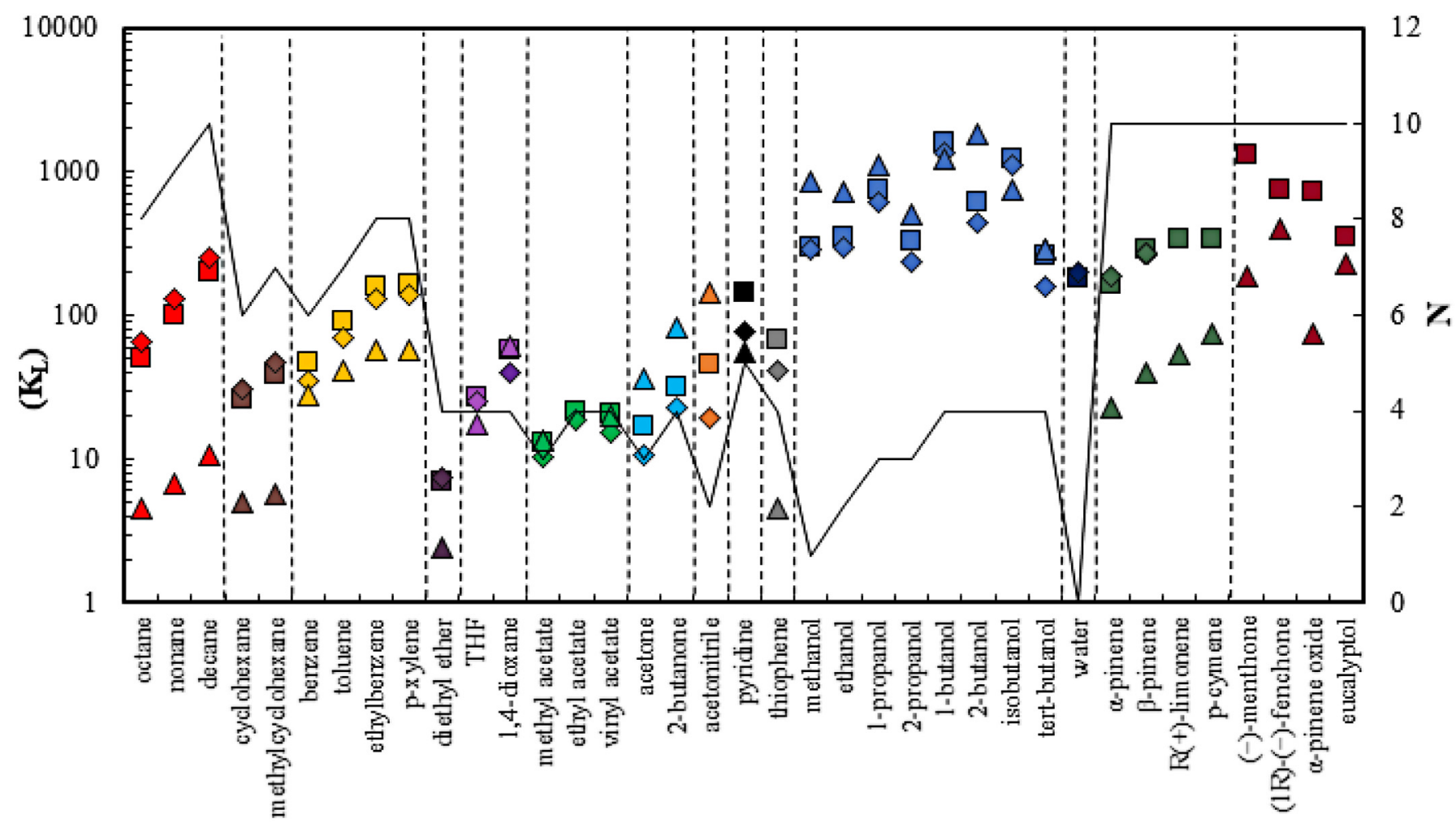

Fig. 2. Gas-liquid partition coefficients $\left(K_{L}\right)$ of several organic solutes and water at $383.15 \mathrm{~K}$ in $\square\left[\mathrm{P}_{6,6,6,14}\right] \mathrm{Cl}_{,} \diamond\left[\mathrm{P}_{6,6,6,14}\right]\left[\left(\mathrm{C}_{8} \mathrm{H}_{17}\right)_{2} \mathrm{PO} \mathrm{O}_{2}\right]$ and $\Delta\left[\mathrm{C}_{4}\right.$ mim $][\mathrm{OAc}]$. 
bonds between the anion $[\mathrm{OAc}]^{-}$and the hydroxyl groups from the alcohols, which increases the solute-solvent affinity in the liquid phase. Considering the ILs $\left[\mathrm{P}_{6,6,6,14}\right] \mathrm{Cl}$ and $\left[\mathrm{P}_{6,6,6,14}\right]\left[\left(\mathrm{C}_{8} \mathrm{H}_{17}\right)_{2} \mathrm{PO}_{2}\right]$, the gasliquid partition coefficients of each solute in the ionic liquids presents the same order of magnitude. By analyzing Table S7 of SI, it is possible to see that some terpenoids, such as geraniol, DL-citronellol, (-)-borneol and L-(-)-menthol, present high $K_{L}$ at higher temperatures, although $K_{L}$ tends to decrease as the temperature increases. From all the calculated values, the lowest partition coefficient was obtained for diethyl ether in $\left[\mathrm{C}_{4} \mathrm{mim}\right][\mathrm{OAc}]$ at $383.15 \mathrm{~K}\left(K_{L}=2.447\right)$, whereas the highest value was found for geraniol in $\left[\mathrm{P}_{6,6,6,14}\right] \mathrm{Cl}$ at $433.15 \mathrm{~K}$ $\left(K_{L}=7114\right)$. The differences between the partition coefficient values in $\left[\mathrm{P}_{6,6,6,14}\right] \mathrm{Cl}$ (moderate $K_{L}$ values were obtained for terpenes and higher $K_{L}$ were found for low volatile terpenoids) suggest this ionic liquid to be a suitable agent for the deterpenation of commercial EOs through distillation, since the volatilization of the hydrocarbon terpenes is facilitated in presence of that IL.

\subsection{Infinite dilution thermodynamic functions}

Partial molar functions at infinite dilution, namely excess Gibbs energy $\left(\bar{G}_{m}^{E, \infty}\right)$, enthalpy $\left(\bar{H}_{m}^{E, \infty}\right)$, and entropy $\left(\bar{S}_{m}^{E, \infty}\right)$ were calculated at $383.15 \mathrm{~K}$ and $433.15 \mathrm{~K}$ for several solutes in the studied ionic liquids. The results are presented in Fig. S3 and in Table S8 of SI. In the three ionic liquids, similar patterns were observed regarding the partial molar thermodynamic functions for alcohols and most of the terpenoids. For these solutes, the $\bar{H}_{m}^{E, \infty}$ and the $\bar{S}_{m}^{E, \infty}$ values are generally negative, suggesting a dominant enthalpic effect in the interactions between the solutes and the IL. Besides, the negative $\ln \left(\gamma_{13}^{\infty}\right)$ values obtained for these solutes indicates that the affinity between the solute and the IL is stronger than the solute-solute or IL-IL interactions, which was qualitatively noticed from the long retention times registered during the GC experiments.

In the case of apolar solutes, such as alkanes, cycloalkanes, aromatic hydrocarbons, and terpenes, in $\left[\mathrm{P}_{6,6,6,14}\right] \mathrm{Cl}$ and $\left[\mathrm{P}_{6,6,6,14}\right]\left[\left(\mathrm{C}_{8} \mathrm{H}_{17}\right)_{2} \mathrm{PO}_{2}\right]$, $\bar{H}_{m}^{E, \infty}$ and $\bar{S}_{m}^{E, \infty}$ are in general positive, and present much lower absolute values (smaller than $3 \mathrm{~kJ} \cdot \mathrm{mol}^{-1}$ ) than the highly polar solutes (alcohols, water and terpenoids). For most of these cases, $\bar{G}_{m}^{E, \infty}$ is close to zero, indicating that the enthalpic and entropic effects cancel each other. For the less polar solutes in $\left[\mathrm{C}_{4} \mathrm{mim}\right][\mathrm{OAc}], \bar{H}_{m}^{E, \infty}$ is generally positive, while $\bar{S}_{m}^{E, \infty}$ is mostly negative, resulting in very positive $\bar{G}_{m}^{E, \infty}$ values.

A more detailed discussion about the solute-IL affinity obtained from these thermodynamic functions is presented in Section 2 of Supporting Information.

\subsection{Selectivities and capacities}

Besides the separation problems discussed in the following sections, the separation of benzene from aliphatic hydrocarbons is addressed in Section S2 of SI, where the selectivities and capacities obtained in this work (at $333.15 \mathrm{~K}$ ) are critically compared with the data available in literature $[69,70]$ and presented in Table S9. In summary, the results show that the experimental data obtained here are in excellent agreement with the data found in literature, and $\left[\mathrm{C}_{4} \mathrm{mim}\right][\mathrm{OAc}]$ presents favorable selectivities, although poor capacities, for the removal of benzene from octane and cyclohexane.

\subsubsection{Terpene mixtures}

A suitable entrainer in liquid-liquid extraction should promote high selectivities $\left(S_{i j}^{\infty}\right)$, and capacities $\left(k_{j}^{\infty}\right)$, to provide an efficient separation of the components without the formation of immiscible mixtures $[71,72]$. Since one of the main perspectives of this work is to explore the performance of the ionic liquids in the fractionation of terpene mixtures, experimental and predicted selectivities and capacities (by COSMO-RS), obtained at $403.15 \mathrm{~K}$, are presented in Fig. 3 (and Tables S10-S15 of SI). In some cases, the experimental selectivities and capacities were extrapolated to $403.15 \mathrm{~K}$ using experimental data obtained at $433.15-458.15 \mathrm{~K}$.

The three ionic liquids showed poor experimental and predicted selectivities $(<2)$ for the terpene/terpene separations such as the $\alpha$ pinene $/ \beta$-pinene, $\beta$-pinene $/ \mathrm{R}(+)$-limonene and $\mathrm{p}$-cymene $/ \mathrm{R}(+)$-limonene mixtures. In particular, the fractionation of $\alpha$-pinene $/ \beta$-pinene mixture is commercially attractive due to the high concentration of these compounds in several essential oils from Pinus species $[73,74]$. However, the similarities between the chemical structures and the physical properties of these compounds are handicaps in the fractionation of this mixture through solvent extraction processes or distillation. Regarding the COSMO-RS predictions, the model provides $S_{i j}^{\infty}$ and $k_{j}^{\infty}$ values which are in very good agreement with the experimental data for most of the studied terpene/terpene separations. Nevertheless, the model shows that the ionic liquids present a higher potential for the fractionation of some terpene/terpenoid mixtures, which is validated by the experimental results.

For $\left[\mathrm{C}_{4} \mathrm{mim}\right][\mathrm{OAc}]$, encouraging experimental selectivities were found for terpene/linalool mixtures, being the highest found for $\mathrm{R}(+)$ limonene/linalool $\left(S_{i j}^{\infty}=30.29\right)$. This particular mixture represents the majority of the components present in Citrus essential oils profiles $[20,22,75]$, and the removal of $\mathrm{R}(+)$-limonene improves the oil stability [21]. The high selectivity value found for the $\mathrm{R}(+)$-limonene/linalool mixture along with the reasonable capacity of linalool (1.26) at $403.15 \mathrm{~K}$ suggest that $\left[\mathrm{C}_{4} \mathrm{mim}\right][\mathrm{OAc}]$ is a potential option in the deterpenation of citrus essential oils, in accordance with the study of Lago et al. [38]. The authors obtained liquid-liquid equilibrium data for $\mathrm{R}\left(+\right.$ )-limonene/ linalool/[ $\left.\mathrm{C}_{4} \mathrm{mim}\right][\mathrm{OAc}]$ ternary systems, concluding that the ionic liquid exhibits a good performance in the deterpenation of citrus essential oil due to the strong affinity of the acetate anion with the hydroxyl group present in linalool.

In the case of $\left[\mathrm{P}_{6,6,6,14}\right] \mathrm{Cl}$ many other separations can be discussed, since the experimental measurements were conducted for a larger set of terpenoids. Despite the low selectivities and capacities obtained for mixtures of terpenes, promising values were found for some terpene/ terpenoid and terpenoid/terpenoid combinations. The experimental selectivity and capacity (at $403.15 \mathrm{~K}$ ) obtained for R(+)-limonene/linalool were $S_{i j}^{\infty}=10.20$ and $k_{j}^{\infty}=9.01$, respectively, suggesting $\left[\mathrm{P}_{6,6,6,14}\right]$ $\mathrm{Cl}$ to be also an appropriate solvent in the deterpenation of citrus oils. In addition, promising selectivities and capacities $\left(S_{i j}^{\infty}=10.16\right.$ and $k_{j}^{\infty}$ $=11.72$ ) were observed for the fractionation of $(-)$-menthone/L(-)-menthol mixture, which can be found in high concentrations in peppermint essential oils [76-78]. Another potential separation problem is the fractionation of the (-)-borneol/camphor mixture, widely present in the essential oils from flowers of the Asteraceae $[79,80]$ and Lamiaceae [81-83] families. Again, a high selectivity $\left(S_{i j}^{\infty}=9.03\right)$ and capacity of $(-)$-borneol $\left(k_{j}^{\infty}=14.15\right)$ were obtained with $\left[\mathrm{P}_{6,6,6,14}\right] \mathrm{Cl}$. For this ionic liquid, the COSMO-RS predictions showed, in general, lower selectivities and capacities. In particular, for the binaries mentioned above for the $\mathrm{R}(+)$-limonene/linalool $\left(S_{i j}^{\infty}=3.59\right.$ and $\left.k_{j}^{\infty}=4.29\right)$, the menthone/L- $(-)$-menthol $\left(S_{i j}^{\infty}=2.44\right.$ and $\left.k_{j}^{\infty}=3.80\right)$, and the (-)-borneol/camphor $\left(S_{i j}^{\infty}=2.33\right.$ and $\left.k_{j}^{\infty}=3.81\right)$ mixtures, but still higher than the values predicted for terpene/terpene mixtures. Although COSMO-RS is able to correctly predict the selectivity ranks and capacity (terpene/ low volatile terpenoid $>$ terpene/terpenoid $>$ terpene/terpene), the real potential of the $\left[\mathrm{P}_{6,6,6,14}\right] \mathrm{Cl}$ for the fractionation of mixtures containing a terpenoid with a hydroxyl group combined with terpene or terpenoids without such a group were obtained from the experimental results.

Good capacities are obtained for most of the solutes in $\left[\mathrm{P}_{6,6,6,14}\right]$ $\left[\left(\mathrm{C}_{8} \mathrm{H}_{17}\right)_{2} \mathrm{PO}_{2}\right]$, but the selectivities are low for most of the binary mixtures studied, being 8.18 the highest experimental value achieved $((1 R)-(-)$-fenchone/linalool) and 4.54 the best predicted value 


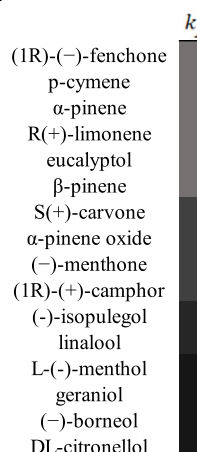$$
k_{j}^{\infty} S_{i j}^{\infty}
$$
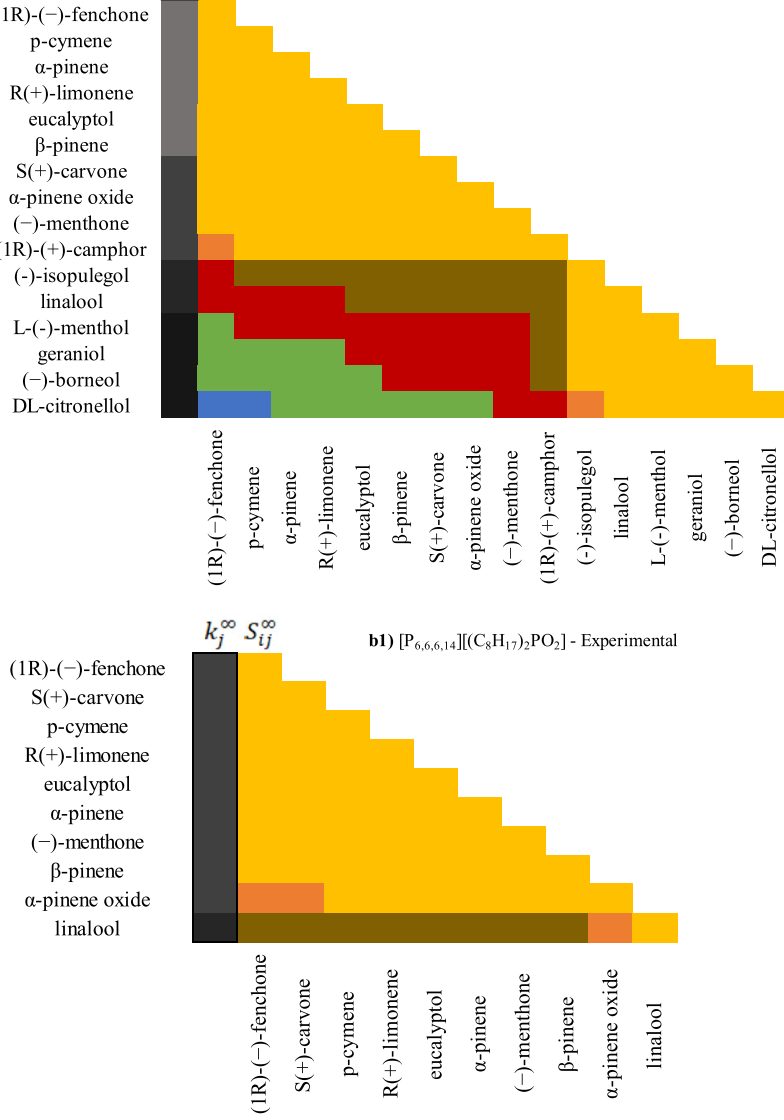

$$
\begin{gathered}
\mathrm{R}(+) \text {-limonene } \\
\alpha \text {-pinene } \\
\beta \text {-pinene } \\
\alpha \text {-pinene oxide } \\
\text { p-cymene } \\
(1 \mathrm{R})-(-) \text {-fenchone } \\
\text { eucalyptol } \\
(-) \text {-menthone } \\
\mathrm{S}(+) \text {-carvone } \\
\text { linalool }
\end{gathered}
$$

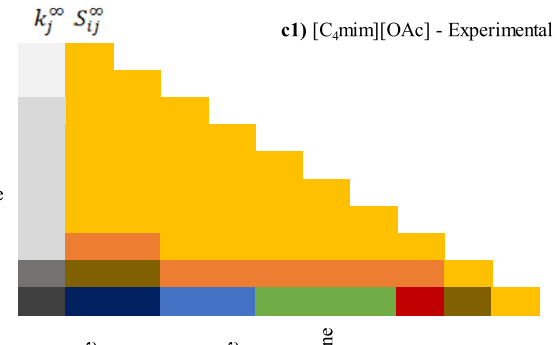

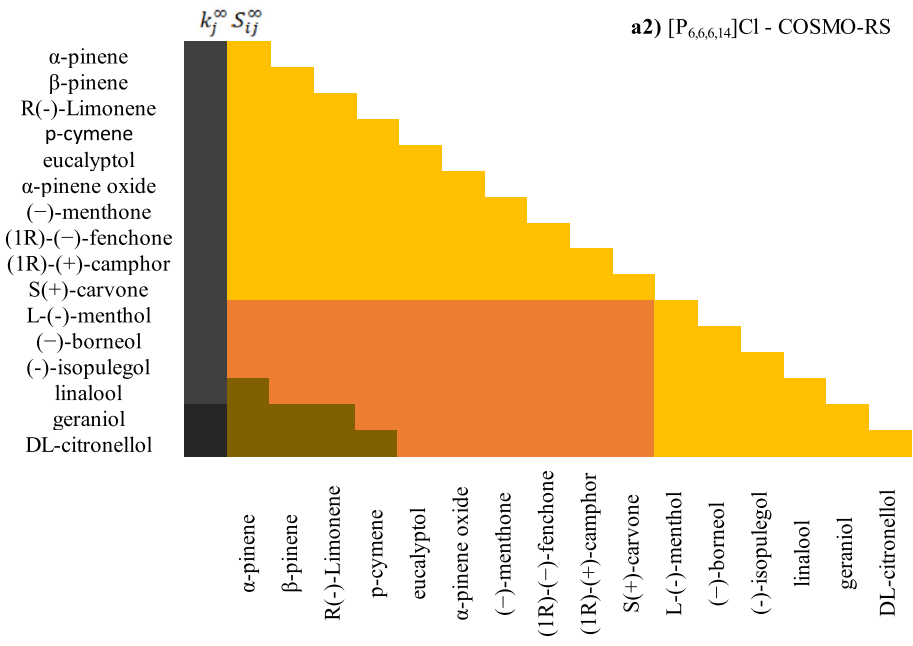
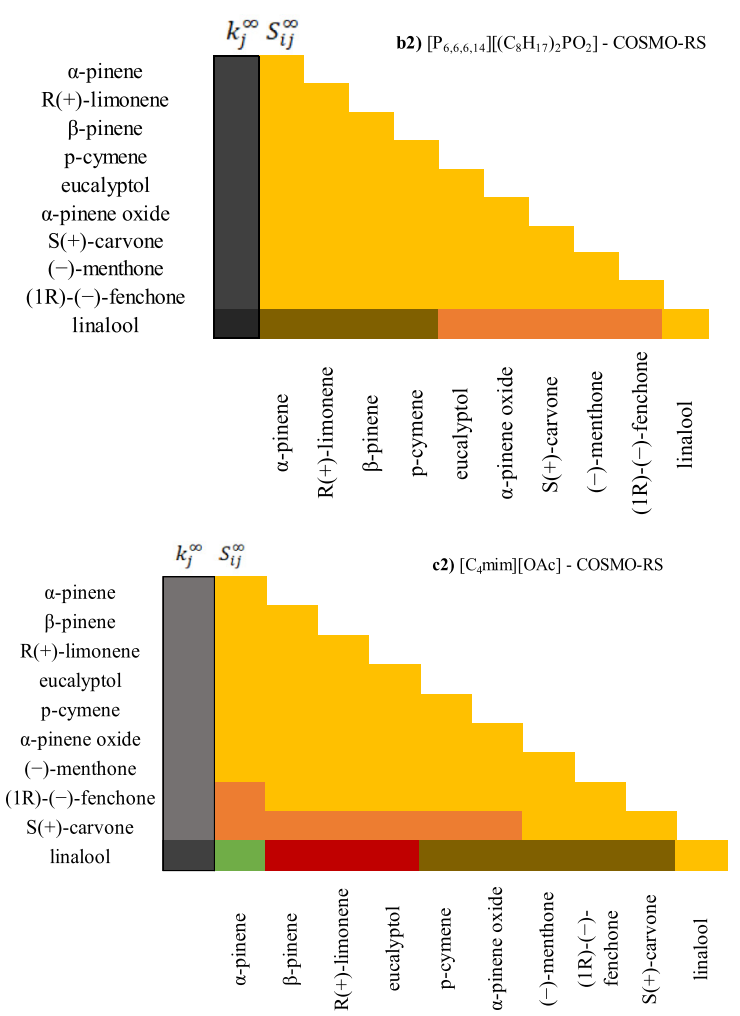

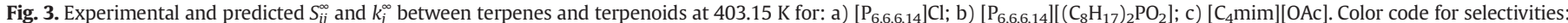

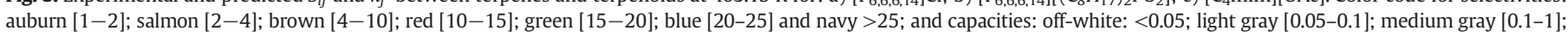
dark gray [1-5]; charcoal [5-10]; and black $>10$.

( $\alpha$-pinene/linalool). In fact, from the analyzed terpenic binary mixtures, $\left[\mathrm{P}_{6,6,6,14}\right]\left[\left(\mathrm{C}_{8} \mathrm{H}_{17}\right)_{2} \mathrm{PO}_{2}\right]$ only presents some separation potential for those containing linalool, which was observed in both experimental and predicted selectivities and capacities. In comparison with $\left[\mathrm{P}_{6,6,6,14}\right]$ $\mathrm{Cl}$ and $\left[\mathrm{C}_{4} \mathrm{mim}\right][\mathrm{OAc}]$, the presence of long alkyl-chains in $\left[\mathrm{P}_{6,6,6,14}\right]^{+}$ and in $\left[\left(\mathrm{C}_{8} \mathrm{H}_{17}\right)_{2} \mathrm{PO}_{2}\right]^{-}$increases the affinity of low polar solutes and [the ionic liquid, resulting in lower selectivities. In a previous study from our group [40], selectivities and capacities for terpene mixtures were calculated (at $408.15 \mathrm{~K}$ ), considering four methylimidazoliumbased ILs: 1-butyl-3-methylimidazolium chloride $\left(\left[\mathrm{C}_{4} \mathrm{mim}\right] \mathrm{Cl}\right)$, 1-butyl-3-methylimidazolium methanesulfonate $\left(\left[\mathrm{C}_{4} \mathrm{mim}\right]\left[\mathrm{CH}_{3} \mathrm{SO}_{3}\right]\right)$, 1-butyl-3-methylimidazolium dimethyl phosphate $\left(\left[\mathrm{C}_{4} \mathrm{mim}\right]\left[\left(\mathrm{CH}_{3}\right)\right.\right.$ $\left.{ }_{2} \mathrm{PO}_{4}\right]$ ) and 1-butyl-3-methylimidazolium trifluoromethanesulfonate
$\left(\left[\mathrm{C}_{4} \mathrm{mim}\right]\left[\mathrm{CF}_{3} \mathrm{SO}_{3}\right]\right)$. In general, the best selectivities and capacities were found for mixtures containing eugenol, thymol, and carvacrol, which were not studied in this work. Moreover, good selectivities and capacities were achieved for terpenic mixtures containing ( - )-borneol, $(-)$-isopulegol, and $(1 R)-(+)$-camphor, which was also observed in this work for $\left[\mathrm{P}_{6,6,6,14}\right] \mathrm{Cl}$. Similarly to the selectivities obtained in this work, for the $\alpha$-pinene/ $\beta$-pinene mixture, the authors also reported poor selectivity using any of the ILs investigated. As discussed before, the fractionation of the $\alpha$-pinene/ $\beta$-pinene mixture is challenging, and the use of ionic liquids or another type of entrainers requires further research. In the case of the (-)-menthone/L-( -$)$-menthol mixture, the most promising selectivities were reported for $\left[\mathrm{C}_{4} \mathrm{mim}\right] \mathrm{Cl}\left(S_{i j}^{\infty}=8.77\right)$, which is close to the value extrapolated at $408.15 \mathrm{~K}$ using the 
Table 2

$S_{i j}^{\infty}$ and $k_{j}^{\infty}$ of octane/thiophene and octane/pyridine separations in imidazolium and phosphonium-based ionic liquids at $333.15 \mathrm{~K}$.

\begin{tabular}{|c|c|c|c|}
\hline \multirow[t]{2}{*}{ Ionic liquid } & \multicolumn{2}{|c|}{ Selectivities $\left(S_{i j}^{\infty}\right) /$ capacities $\left(k_{j}^{\infty}\right)$} & \multirow[t]{2}{*}{ Reference } \\
\hline & Octane/thiophene & Octane/pyridine & \\
\hline \multicolumn{4}{|c|}{ Phosphonium-based ionic liquids } \\
\hline$\left[\mathrm{P}_{1,4,4,4}\right] \mathrm{TOS}$ & $19.20 / 1.21^{\mathrm{a}}$ & - & {$[88]$} \\
\hline$\left[P_{2,4,4,4}\right][D E P]$ & $8.23 / 1.71^{\mathrm{a}}$ & $8.81 / 1.84^{\mathrm{a}}$ & [89] \\
\hline$\left[\mathrm{P}_{14,6,6,6}\right]\left[\mathrm{NTf}_{2}\right]$ & $3.63 / 2.57^{\mathrm{a}}$ & $3.81 / 2.70^{\mathrm{a}}$ & {$[90]$} \\
\hline$\left[\mathrm{P}_{6,6,6,14}\right] \mathrm{Br}$ & - & $3.89 / 2.09$ & [91] \\
\hline \multirow[t]{2}{*}[\mathrm{P}_{6,6,6,6,14}]{$\mathrm{Cl}$} & $4.93 / 2.81$ & $4.17 / 2.38$ & This work ${ }^{\mathrm{c}}$ \\
\hline & $3.46 / 2.22$ & $4.93 / 2.81$ & This work $^{\mathrm{d}}$ \\
\hline \multirow{2}{*}[\mathrm{P}_{6,6,6,14}]{$\left[\left(\mathrm{C}_{8} \mathrm{H}_{17}\right)_{2} \mathrm{PO}_{2}\right]$} & $1.62 / 1.90$ & $1.44 / 1.70$ & This work ${ }^{\mathrm{c}}$ \\
\hline & $1.84 / 2.14$ & $1.29 / 1.50$ & This work ${ }^{\mathrm{d}}$ \\
\hline \multicolumn{4}{|c|}{ 1-butyl-3-methylmidazolium-based ionic liquids } \\
\hline$\left[\mathrm{C}_{4} \mathrm{mim}\right] \mathrm{Cl}$ & $243.46 / 0.58^{\mathrm{b}}$ & $347.97 / 0.82^{\mathrm{b}}$ & [39] \\
\hline$\left[\mathrm{C}_{4} \mathrm{mim}\right]\left[\mathrm{BF}_{4}\right]$ & $190.03 / 0.67^{\mathrm{b}}$ & $312.60 / 1.06^{\mathrm{b}}$ & {$[92]$} \\
\hline$\left[\mathrm{C}_{4} \mathrm{mim}\right][\mathrm{SCN}]$ & $180.34 / 0.78^{\mathrm{a}}$ & - & [93] \\
\hline$\left[\mathrm{C}_{4} \mathrm{mim}\right]\left[\mathrm{CHSO}_{3}\right]$ & $129.81 / 0.69^{b}$ & $16.37 / 0.09^{\mathrm{b}}$ & [39] \\
\hline$\left[\mathrm{C}_{4} \mathrm{mim}\right][\mathrm{DCA}]$ & $109.23 / 0.87^{\mathrm{b}}$ & $137.43 / 1.09^{\mathrm{b}}$ & {$[94]$} \\
\hline$\left[\mathrm{C}_{4} \mathrm{mim}\right][\mathrm{TCM}]$ & $87.59 / 1.49^{a}$ & $96.13 / 1.64^{\mathrm{a}}$ & [95] \\
\hline$\left[\mathrm{C}_{4} \mathrm{mim}\right]\left[\mathrm{PF}_{6}\right]$ & $66.37 / 0.68$ & $120.46 / 1.23$ & [96] \\
\hline$\left[\mathrm{C}_{4} \mathrm{mim}\right][\mathrm{TOS}]$ & $60.38 / 0.91^{\mathrm{a}}$ & - & [97] \\
\hline$\left[\mathrm{C}_{4} \mathrm{mim}\right]\left[\left(\mathrm{CH}_{3}\right)_{2} \mathrm{PO}_{4}\right]$ & $51.81 / 0.98^{\mathrm{b}}$ & $51.07 / 0.97^{\mathrm{b}}$ & [39] \\
\hline$\left[\mathrm{C}_{4} \mathrm{mim}\right]\left[\mathrm{CF}_{3} \mathrm{SO}_{3}\right]$ & $50.60 / 0.86^{a}$ & - & [98] \\
\hline$\left[\mathrm{C}_{4} \mathrm{mim}\right][\mathrm{BETI}]$ & $17.49 / 1.68^{\mathrm{a}}$ & $32.5 / 3.13^{\mathrm{a}}$ & [99] \\
\hline$\left[\mathrm{C}_{4} \mathrm{mim}\right]\left[\left[\mathrm{C}_{8} \mathrm{H}_{17} \mathrm{OS}_{\mathrm{O} 3}\right]\right.$ & $10.10 / 1.28^{\mathrm{a}}$ & - & {$[100]$} \\
\hline$\left[\mathrm{C}_{4} \mathrm{mim}\right]\left[\mathrm{n}-\mathrm{C}_{18} \mathrm{H}_{35} \mathrm{OO}\right]$ & $2.00 / 1.25$ & - & [101] \\
\hline$\left[\mathrm{C}_{4} \mathrm{mim}\right]\left[\mathrm{n}-\mathrm{C}_{16} \mathrm{H}_{31} \mathrm{OO}\right]$ & $1.78 / 1.11$ & - & [101] \\
\hline \multirow[t]{2}{*}[\mathrm{C}_{4}\mathrm{mim}]{$[\mathrm{OAc}]$} & $69.54 / 0.81$ & $67.89 / 0.78$ & This work ${ }^{\mathrm{c}}$ \\
\hline & $18 / 72 / 1.11$ & $17.67 / 1.05$ & This work $^{\mathrm{d}}$ \\
\hline
\end{tabular}

\footnotetext{
a Interpolated using the data reported by the authors.

b Extrapolated using the data reported by the authors.

Experimental values.
}

d Predicted using COSMO-RS.

experimental data obtained here for $\left[\mathrm{P}_{6,6,6,14}\right] \mathrm{Cl}\left(S_{i j}^{\infty}=9.88\right)$. However, a major difference is observed for the capacities of L-(-)-menthol: $k_{j}^{\infty}=$ 0.10 for $\left[\mathrm{C}_{4} \mathrm{mim}\right] \mathrm{Cl}$ and $k_{j}^{\infty}=10.84$ for $\left[\mathrm{P}_{6,6,6,14}\right] \mathrm{Cl}$, indicating that this is a more suitable option as separation agent for the fractionation of peppermint essential oils.

\subsubsection{Desulfurization and denitrification of fossil fuels}

The emission of sulfur- and nitrogen-compounds from the burning of fossil fuels is a known cause of acid rain, and respiratory diseases $[84,85]$. Environmental regulations aiming at the reduction of the emissions [5,84], and new limits for the sulfur and nitrogen containing compounds in the fuels require alternatives to the traditional separation techniques. The use of ionic liquids is promising, since they are usually capable of solubilizing the nitrogen and sulfur-based components, while presenting low affinity for the aliphatic hydrocarbons of the fuels $[86,87]$. The potentialities of $\left[\mathrm{P}_{6,6,6,14}\right] \mathrm{Cl}$, $\left[\mathrm{P}_{6,6,6,14}\right]\left[\left(\mathrm{C}_{8} \mathrm{H}_{17}\right)_{2} \mathrm{PO}_{2}\right]$ and $\left[\mathrm{C}_{4} \mathrm{mim}\right][\mathrm{OAc}]$ in the desulfurization and denitrification of fuels are, therefore, here evaluated in terms of the selectivities and capacities for the octane/thiophene and octane/pyridine separations. Table 2 compares the information obtained in this work (at $333.15 \mathrm{~K}$ ), with the data reported in literature for other phosphonium-based and 1-butyl-3mehylimidazolium-based ionic liquids.

The selectivities reported for 1-butyl-3-methylmidazolium-based ionic liquids are usually higher for both octane/thiophene and octane/ pyridine separations than the selectivities of the phosphonium-based ILs, while the capacities generally tend to be the opposite. From all the ionic liquids presented in Table 2, the most appropriate options to perform both desulfurization and denitrification of fossil fuels are [ $\left.\mathrm{C}_{4} \mathrm{mim}\right]$ $\mathrm{Cl}$ and $\left[\mathrm{C}_{4} \mathrm{mim}\right]\left[\mathrm{BF}_{4}\right]$, since both ILs present considerably high selectivities and acceptable capacity values. In the case of the ILs studied in this work, [ $\left.\mathrm{C}_{4} \mathrm{mim}\right][\mathrm{OAc}]$ presents the highest selectivity, being also an adequate option for the removal of sulfur-based and nitrogen-based contaminates from fuel oils.

As discussed before, the capacity plays an important role in the solvent selection, and very low capacities must be rejected. However, low selectivities could imply poor separation efficiency, making the separation difficult or not viable. In general, the ionic liquids composed by phosphonium cations present satisfactory capacities (always higher than 1), but their low selectivities for the octane/thiophene and octane/pyridine mixtures limits the use of these ILs. A clear exception is $\left[\mathrm{P}_{1,4,4,4}\right] \mathrm{TOS}$, which presents a high selectivity and reasonable capacity for the removal of thiophene from aliphatic hydrocarbons. A possibility to be explored in the future is the use of mixtures of two or more ionic liquids as the GC stationary phase, as previously reported by Shida and co-authors [102]. The presence of two phosphonium-based ILs with different selectivities and capacities (e.g., the equimolar mixture of $\left[\mathrm{P}_{1,4,4,4}\right]$ TOS and $\left[\mathrm{P}_{6,6,6,14}\right] \mathrm{Cl}$ ) could increase capacity values, while retaining the good selectivities for the desulfurization of fossil fuels.

The predictions of COSMO-RS are in excellent agreement with the experimental values for the phosphonium-based ILs, whereas more significant deviations are observed for the highly polar $\left[\mathrm{C}_{4} \mathrm{mim}\right][\mathrm{OAc}]$. In fact, it is expected that COSMO-RS predictions present larger errors for systems containing highly polar compounds, since the model is unable to take into account some specific hydrogen bonds [59,103]. Nevertheless, the COSMO-RS model provided a prior qualitative estimations of $S_{i j}^{\infty}$ and $k_{j}^{\infty}$ values for both octane/thiophene and octane/pyridine mixtures, suggesting that the model is a reliable tool to be used in the screening of potential entrainers for these separation problems.

\section{Conclusions}

In this work, the potential of $\left[\mathrm{P}_{6,6,6,14}\right] \mathrm{Cl},\left[\mathrm{P}_{6,6,6,14}\right]\left[\left(\mathrm{C}_{8} \mathrm{H}_{17}\right)_{2} \mathrm{PO}_{2}\right]$ and $\left[\mathrm{C}_{4} \mathrm{mim}\right][\mathrm{OAc}]$ as separation agents for relevant industrial separations problems was investigated through experimental and modeling approaches. The activity coefficients at infinite dilution and the gasliquid partition coefficients were experimentally obtained for water, common organic solvents and terpenes in the three ionic liquids by gas-chromatography, in the temperature range 333.15-453.15 $\mathrm{K}$. The differences between the gas-liquid partition coefficients for terpenes and low volatile terpenoids indicate that $\left[\mathrm{P}_{6,6,6,14}\right] \mathrm{Cl}$ holds a good potential as agent for the purification of terpenic mixtures.

The excess partial molar properties $\left(\bar{H}_{m}^{E, \infty}, \bar{S}_{m}^{E, \infty}\right.$ and $\left.\bar{G}_{m}^{E, \infty}\right)$ were derived from the activity coefficients. The results show that the strong polar solutes present high affinity with the ILs dominated by enthalpic contributions, whereas the interactions between the less polar solutes and the ionic liquids are weaker, especially for $\left[\mathrm{C}_{4} \mathrm{mim}\right][\mathrm{OAc}]$.

Selectivities and capacities were calculated from the experimental values to evaluate the efficiency of the ILs as entrainers in the separation of aromatics from aliphatic compounds, the fractionation of essential oils, and the desulfurization and denitrification of fossil fuels. The experimental results were also compared with the estimated $S_{i j}^{\infty}$ and $k_{j}^{\infty}$ from the predictive COSMO-RS model. Both experimental and modeling approaches showed that $\left[\mathrm{C}_{4} \mathrm{mim}\right][\mathrm{OAc}]$ is an interesting option for removing sulfur and nitrogen impurities of fossil fuels. This IL also presents relevant selectivity values for the removal of benzene from alkanes and cycloalkanes, and it is an excellent candidate for the deterpenation of orange essential oils. The three ILs studied in this work are suitable separation agents, in terms of selectivities and capacities, for the fractionation of limonene/linalool mixtures, which corresponds to the major fraction of several citrus essential oils.

The $S_{i j}^{\infty}$ and $k_{j}^{\infty}$ values calculated for terpenic mixtures in presence of $\left[\mathrm{P}_{6,6,6,14}\right] \mathrm{Cl}$ also reveal an excellent potential for the fractionation of other major components of EOs, namely menthone/menthol, and borneol/camphor. However, the ILs studied in this work present poor 
selectivity and capacity for all terpene/terpene mixtures, including the complex $\alpha$-pinene/ $\beta$-pinene separation problem. In general, the trends obtained from the experimental selectivities and capacities for the fractionation of the terpenic mixtures were also observed in the predicted results, even though COSMO-RS usually underestimated them, presenting bigger deviations for mixtures containing hydrogen-bond donor terpenoids with an IL with a hydrogen-bond acceptor character. Therefore, the COSMO-RS holds a good potential to screen separation agents for the fractionation of mixtures containing terpenes, including several essential oils, as well as the separation of impurities from fossil fuels.

\section{CRediT authorship contribution statement}

Sérgio M. Vilas-Boas: Investigation, Writing - original draft, Data curation, Software. Gabriel Teixeira: Investigation. Sabrina Rosini: Investigation. Mónia A.R. Martins: Investigation, Data curation. Priscilla S. Gaschi: Writing - review \& editing. João A.P. Coutinho: Supervision, Writing - review \& editing. Olga Ferreira: Supervision, Project administration, Writing - review \& editing. Simão P. Pinho: Supervision, Project administration, Writing - review \& editing.

\section{Declaration of Competing Interest}

The authors declare that they have no known competing financial interests or personal relationships that could have appeared to influence the work reported in this paper.

\section{Acknowledgements}

This work was developed within the scope of the project CICECOAveiro Institute of Materials, UIDB/50011/2020 \& UIDP/50011/2020, and CIMO-Mountain Research Center, UIDB/00690/2020, both financed by national funds through the Portuguese Foundation for Science and Technology/MCTES. Sérgio M. Vilas-Boas also thanks FCT for the Ph.D. grant (SFRH/BD/138149/2018).

\section{Appendix A. Supplementary Data}

Supplementary data to this article can be found online at https://doi. org/10.1016/j.molliq.2020.114647.

\section{References}

[1] P. Wasserscheid, T. Welton, Ionic Liquids in Synthesis, First ed. Wiley-VCH Verlag GmbH \& Co, KGaA, 2002.

[2] K. Paduszyński, An overview of the performance of the COSMO-RS approach in predicting the activity coefficients of molecular solutes in ionic liquids and derived properties at infinite dilution, Phys. Chem. Chem. Phys. 19 (2017) 11835-11850.

[3] S.P.M. Ventura, F.A.E. Silva, M.V. Quental, D. Mondal, M.G. Freire, J.A.P. Coutinho, Ionic-liquid-mediated extraction and separation processes for bioactive compounds: Past, present, and future trends, Chem. Rev. 117 (2017) 6984-7052.

[4] H. Zhao, S. Xia, P. Ma, Use of ionic liquids as "green" solvents for extractions, J. Chem. Technol. Biotechnol. 80 (2005) 1089-1096.

[5] M.H. Ibrahim, M. Hayyan, M.A. Hashim, A. Hayyan, The role of ionic liquids in desulfurization of fuels: A review, Renew. Sust. Energ. Rev. 76 (2017) 1534-1549.

[6] R. Abro, M. Abro, S. Gao, A.W. Bhutto, Z.M. Ali, A. Shah, X. Chen, G. Yu, Extractive denitrogenation of fuel oils using ionic liquids: A review, RSC Adv. 6 (2016) 93932-93946.

[7] M.J. Salar-García, V.M. Ortiz-Martínez, F.J. Hernández-Fernández, A.P. de los Ríos, J. Quesada-Medina, Ionic liquid technology to recover volatile organic compounds (VOCs), J. Hazard. Mater. 321 (2017) 484-499.

[8] P. Navarro, A. Ovejero-Pérez, M. Ayuso, N. Delgado-Mellado, M. Larriba, J. García, F. Rodríguez, Cyclohexane/cyclohexene separation by extractive distillation with cyano-based ionic liquids, J. Mol. Liq. 289 (2019).

[9] K. Paduszyński, In silico calculation of infinite dilution activity coefficients of molecular solutes in ionic liquids: Critical review of current methods and new models based on three machine learning algorithms, J. Chem. Inf. Model. 56 (2016) 1420-1437.

[10] A. Marciniak, Influence of cation and anion structure of the ionic liquid on extraction processes based on activity coefficients at infinite dilution. A review, Fluid Phase Equilib. 294 (2010) 213-233.
[11] K.G. Ramawat, J.-M. Mérillon, Natural Products: Phytochemistry, Botany and Metabolism of Alkaloids, Phenolics and Terpenes, Springer-Verlag, Berlin Heidelberg, 2013.

[12] F. Bakkali, S. Averbeck, D. Averbeck, M. Idaomar, Biological effects of essential oils A review, Food Chem. Toxicol. 46 (2008) 446-475.

[13] S. Patel, Plant essential oils and allied volatile fractions as multifunctional additives in meat and fish-based food products: A review, Food Addit. Contam. - Part A Chem. Anal. Control. Expo. Risk Assess. 32 (2015) 1049-1064.

[14] P. Tongnuanchan, S. Benjakul, Essential oils: extraction, bioactivities, and their uses for food preservation, J. Food Sci. 79 (2014) 1231-1249.

[15] A. Sarkic, I. Stappen, Essential oils and their single compounds in cosmetics - A critical review, Cosmetics. 5 (2018) 1-21.

[16] I.T. Carvalho, B.N. Estevinho, L. Santos, Application of microencapsulated essential oils in cosmetic and personal healthcare products - A review, Int. J. Cosmet. Sci. 38 (2016) 109-119.

[17] Y. Bhalla, V.K. Gupta, V. Jaitak, Anticancer activity of essential oils: A review, J. Sci. Food Agric. 93 (2013) 3643-3653.

[18] Z.A.A. Aziz, A. Ahmad, S.H.M. Setapar, A. Karakucuk, M.M. Azim, D. Lokhat, M. Rafatullah, M. Ganash, M.A. Kamal, G.M. Ashraf, Essential oils: extraction techniques, pharmaceutical and therapeutic potential - A review, Curr. Drug Metab. 19 (2018) 1100-1110.

[19] J.S. Raut, S.M. Karuppayil, A status review on the medicinal properties of essential oils, Ind. Crop. Prod. 62 (2014) 250-264.

[20] A. Arce, A. Soto, Citrus essential oils: Extraction and deterpenation, Tree For. Sci. Biotechnol. 2 (2008) 1-9.

[21] J. Owsu-Yaw, R.F. Matthews, P.F. West, Alcohol deterpenation of orange oil, J. Food Sci. 51 (1986) 1180-1182.

[22] B. Ozturk, J. Esteban, M. Gonzalez-Miquel, Deterpenation of citrus essential oils using glycerol-based deep eutectic solvents, J. Chem. Eng. Data 63 (2018) 2384-2393.

[23] G. Ben Salha, R. Herrera Díaz, J. Labidi, M. Abderrabba, Deterpenation of Origanum majorana L. essential oil by reduced pressure steam distillation, Ind. Crops Prod. 109 (2017) 116-122.

[24] X.M. Li, S.L. Tian, Z.C. Pang, J.Y. Shi, Z.S. Feng, Y.M. Zhang, Extraction of Cuminum cyminum essential oil by combination technology of organic solvent with low boiling point and steam distillation, Food Chem. 115 (2009) 1114-1119.

[25] A. Arce, A. Marchiaro, J.M. Martínez-Ageitos, A. Soto, Citrus essential oil deterpenation by liquid-liquid extraction, Can. J. Chem. Eng. 83 (2008) 366-370.

[26] C. Chiyoda, M.C. Capellini, I.M. Geremias, F.H. Carvalho, K.K. Aracava, R.S. Bueno, C.B. Gonçalves, C.E.C. Rodrigues, Deterpenation of bergamot essential oil using liquid-liquid extraction: Equilibrium data of model systems at $298.2 \mathrm{~K}$, J. Chem. Eng. Data 56 (2011) 2362-2370.

[27] C.C. Koshima, M.C. Capellini, I.M. Geremias, K.K. Aracava, C.B. Gonçalves, C.E.C. Rodrigues, Fractionation of lemon essential oil by solvent extraction: Phase equilibrium for model systems at $\mathrm{T}=298.2 \mathrm{~K}$, J. Chem. Thermodyn. 54 (2012) 316-321.

[28] D. Gonçalves, C.C. Koshima, K.T. Nakamoto, T.K. Umeda, K.K. Aracava, C.B. Gonçalves, C.E.D.C. Rodrigues, Deterpenation of eucalyptus essential oil by liquid + liquid extraction: Phase equilibrium and physical properties for model systems at T $=298.2 \mathrm{~K}$, J. Chem. Thermodyn. 69 (2014) 66-72.

[29] M.C. Capellini, F.H. Carvalho, C.C. Koshima, K.K. Aracava, C.B. Gonçalves, C.E.C. Rodrigues, Phase equilibrium data for systems composed of oregano essential oil compounds and hydroalcoholic solvents at T $=298.2 \mathrm{~K}$, J. Chem. Thermodyn. 88 (2015) 61-71.

[30] C.C. Koshima, T.K. Umeda, K.T. Nakamoto, L.L. Venâncio, K.K. Aracava, C.E.C. Rodrigues, (Liquid + liquid) equilibrium for systems composed of clove and allspice essential oil compounds and hydrous ethanol at $\mathrm{T}=298.2 \mathrm{~K}$, J. Chem. Thermodyn. 95 (2016) 54-62.

[31] D. Gonçalves, M.F. Paludetti, C.B. Gonçalves, C.E.C. Rodrigues, Extraction of oxygenated compounds from crude citrus latifolia peel oil using ethanol/water mixtures as solvents: Phase equilibrium and continuous equipment operation, Sep. Purif. Technol. 199 (2018) 271-281.

[32] B. Ozturk, M. Gonzalez-Miquel, Alkanediol-based deep eutectic solvents for isolation of terpenoids from citrus essential oil: Experimental evaluation and COSMORS studies, Sep. Purif. Technol. 227 (2019) 1-9.

[33] A. Arce, A. Marchiaro, O. Rodríguez, A. Soto, Essential oil terpenless by extraction using organic solvents or ionic liquids, AICHE J. 52 (2006) 2089-2097.

[34] A. Arce, A. Pobudkowska, O. Rodríguez, A. Soto, Citrus essential oil terpenless by extraction using 1-ethyl-3-methylimidazolium ethylsulfate ionic liquid: Effect of the temperature, Chem. Eng. J. 133 (2007) 213-218.

[35] M. Francisco, S. Lago, A. Soto, A. Arce, Essential oil deterpenation by solvent extraction using 1-ethyl-3-methylimidazolium 2-(2-methoxyethoxy) ethylsulfate ionic liquid, Fluid Phase Equilib. 296 (2010) 149-153.

[36] S. Lago, H. Rodríguez, A. Soto, A. Arce, Deterpenation of citrus essential oil by liquid-liquid extraction with 1-alkyl-3-methylimidazolium bis (trifluoromethylsulfonyl)amide ionic liquids, J. Chem. Eng. Data 56 (2011) 1273-1281.

[37] S. Lago, H. Rodríguez, A. Soto, A. Arce, Alkylpyridinium alkylsulfate ionic liquids as solvents for the deterpenation of citrus essential oil, Sep. Sci. Technol. 47 (2012) 292-299.

[38] S. Lago, H. Rodríguez, A. Arce, A. Soto, Improved concentration of citrus essential oil by solvent extraction with acetate ionic liquids, Fluid Phase Equilib. 361 (2014) 37-44.

[39] M.A.R. Martins, J.A.P. Coutinho, S.P. Pinho, U. Domańska, Measurements of activity coefficients at infinite dilution of organic solutes and water on polar imidazoliumbased ionic liquids, J. Chem. Thermodyn. 91 (2015) 194-203. 
[40] M.A.R. Martins, U. Domańska, B. Schröder, J.A.P. Coutinho, S.P. Pinho, Selection of ionic liquids to be used as separation agents for terpenes and terpenoids, ACS Sustain. Chem. Eng. 4 (2016) 548-556.

[41] R. Putnam, R. Taylor, A. Klamt, F. Eckert, M. Schiller, Prediction of infinite dilution activity coefficients using COSMO-RS, Ind. Eng. Chem. Res. 42 (2003) 3635-3641.

[42] R. Anantharaj, T. Banerjee, COSMO-RS based predictions for the desulphurization of diesel oil using ionic liquids: Effect of cation and anion combination, Fuel Process. Technol. 92 (2011) 39-52.

[43] G. Gonfa, M.A. Bustam, T. Murugesan, Z. Man, M.I.A. Mutalib, COSMO-RS based screening ionic liquids for separation of benzene and cyclohexane, Int. J. Chem. Environ. Eng. 3 (2012) 244-254

[44] A.A.P. Kumar, T. Banerjee, Thiophene separation with ionic liquids for desulphurization: A quantum chemical approach, Fluid Phase Equilib. 278 (2009) 1-8.

[45] R. Anantharaj, T. Banerjee, COSMO-RS-based screening of ionic liquids as green solvents in denitrification studies, Ind. Eng. Chem. Res. 49 (2010) 8705-8725.

[46] Z. Lyu, T. Zhou, L. Chen, Y. Ye, K. Sundmacher, Z. Qi, Reprint of: Simulation based ionic liquid screening for benzene-cyclohexane extractive separation, Chem. Eng. Sci. 115 (2014) 186-194.

[47] C. Devi Wilfred, Z. Man, Z. Phak Chan, Predicting methods for sulfur removal from model oils using COSMO-RS and partition coefficient, Chem. Eng. Sci. 102 (2013) 373-377.

[48] Z. Song, T. Zhou, J. Zhang, H. Cheng, L. Chen, Z. Qi, Screening of ionic liquids for solvent-sensitive extraction -with deep desulfurization as an example, Chem. Eng. Sci. 129 (2015) 69-77.

[49] M.C. Castro, A. Arce, A. Soto, H. Rodríguez, Liquid-liquid equilibria of mutually immiscible ionic liquids with a common anion of basic character, J. Chem. Thermodyn. 102 (2016) 12-21.

[50] D.I. for P.P.D. (U.S.), A.I. of C. Engineers., N.I. of S. and T. (U.S.), DIPPR Project 801 Full Version, Design Institute for Physical Property Research/AIChE, 2010.

[51] D.H. Everett, Effect of gas imperfection on G.L.C. measurements: A refined method for determining activity coefficients and second virial coefficients, Trans. Faraday Soc. 61 (1965) 1637-1645.

[52] A.J.B. Cruickshank, B.W. Gainey, C.P. Hicks, T.M. Letcher, R.W. Moody, C.L. Young, Gas-liquid chromatographic determination of cross-term second virial coefficients using glycerol, Trans. Faraday Soc. 65 (1969) 1014-1031.

[53] L.M. Blumberg, Properties of James-Martin compressibility correction factor, Chromatographia. 44 (1997) 326-329.

[54] C. Tsonopoulos, An empirical correlation of second virial coefficients, AICHE J. 20 (1974) 263-272.

[55] C. Tsonopoulos, Second virial cross-coefficients: Correlation and prediction of kij, in: K.C. Chao, R.L.R. Jr (Eds.), Equations State Eng. Res, American Chemical Society 1979, pp. 143-162.

[56] B.E. Poling, J.M. Prausnitz, J.P. O'Connel, The Properties of Gases and Liquids, 5th ed McGraw-Hill, 2001.

[57] R.C. Castells, Determination of gas-liquid partition coefficients by gas chromatography, J. Chromatogr. A 1037 (2004) 223-231.

[58] M. Diedenhofen, A. Klamt, COSMO-RS as a tool for property prediction of IL mixtures-A review, Fluid Phase Equilib. 294 (2010) 31-38.

[59] A. Klamt, F. Eckert, W. Arlt, COSMO-RS: An alternative to simulation for calculating thermodynamic properties of liquid mixtures, Annu. Rev. Chem. Biomol. Eng. 1 (2010) 101-122.

60] A. Klamt, Conductor-like screening model for real solvents: A new approach to the quantitative calculation of solvation phenomena, J. Phys. Chem. 99 (1995) 2224-2235.

[61] A. Klamt, V. Jonas, T. Bürger, J.C.W. Lohrenz, Refinement and parametrization of COSMO-RS, J. Phys. Chem. A 102 (1998) 5074-5085.

[62] A. Klamt, F. Eckert, COSMO-RS: A novel and efficient method for the a priori prediction of thermophysical data of liquids, Fluid Phase Equilib. 172 (2000) 43-72.

[63] M. Diedenhofen, F. Eckert, A. Klamt, Prediction of infinite dilution activity coefficients of organic compounds in ionic liquids using COSMO-RS, J. Chem. Eng. Data 48 (2003) 475-479.

[64] C. Steffen, K. Thomas, U. Huniar, A. Hellweg, O. Rubner, A. Schroer, Software news and updates TmoleX-A graphical user interface for TURBOMOLE, J. Computat. Chem. 31 (2010) 2967-2970.

[65] F. Eckert, A. Klamt, Fast solvent screening via quantum chemistry: COSMO-RS approach, AICHE J. 48 (2002) 369-385

[66] COSMOtherm, C3.0, release 17.01, Cosmol, GmbH Co KG, 2017http://www. cosmologic.de/.

[67] A. Stark, Ionic liquid structure-induced effects on organic reactions, Top. Curr. Chem. 290 (2009) 41-81.

[68] H.F.D. Almeida, J.N.C. Lopes, L.P.N. Rebelo, J.A.P. Coutinho, M.G. Freire, I.M. Marrucho, Densities and viscosities of mixtures of two ionic liquids containing a common cation, J. Chem. Eng. Data 61 (2016) 2828-2843.

[69] T. Banerjee, A. Khanna, Infinite dilution activity coefficients for trihexyltetradecyl phosphonium ionic liquids: Measurements and COSMO-RS prediction, J. Chem. Eng. Data 51 (2006) 2170-2177.

[70] T.M. Letcher, D. Ramjugernath, M. Laskowska, M. Królikowski, P. Naidoo, U. Domańska, Activity coefficients at infinite dilution measurements for organic solutes in the ionic liquid trihexyltetradecylphosphonium-bis-(2,4,4trimethylpentyl)-phosphinate using g.l.c. at $\mathrm{T}=(303.15,308.15,313.15$, and 318.15) K, J. Chem. Thermodyn. 40 (2008) 1243-1247.

[71] Z. Lei, C. Dai, J. Zhu, B. Chen, Extractive distillation with ionic liquids: A review, AICHE J. 60 (2014) 3312-3329.
[72] B. Kabane, G.G. Redhi, Thermodynamic properties and activity coefficients at infinite dilution for different solutes in deep eutectic solvent: 1-butyl-3methylimidazolium chloride + glycerol, J. Mol. Liq. 311 (2020) 113216.

[73] K. Kurose, D. Okamura, M. Yatagai, Composition of the essential oils from the leaves of nine Pinus species and the cones of three of Pinus species, Flavour Fragr. J. 22 (2007) 228-232

[74] E. Ioannou, A. Koutsaviti, O. Tzakou, V. Roussis, The genus Pinus: A comparative study on the needle essential oil composition of 46 pine species, Phytochem. Rev. 13 (2014) 741-768.

175] D. Gonçalves, M.F. Paludetti, P.M. Florido, C. Tonetti, C.B. Gonçalves, C.E.C. Rodrigues, Physical behavior of the phases from the liquid-liquid equilibrium of citrus essential oils systems at 298.2 K, J. Chem. Eng. Data 63 (2018) 2718-2737.

[76] M. Moghaddam, M. Pourbaige, H.K. Tabar, N. Farhadi, S.M.A. Hosseini, Composition and antifungal activity of peppermint (Mentha piperita) essential oil from Iran, J. Essent. Oil-Bearing Plants. 16 (2013) 506-512.

[77] LP. Stanojevic, J.S. Stanojevic, V.L. Savic, D.J. Cvetkovic, A. Kolarevic, Z MarjanovicBalaban, L.B. Nikolic, Peppermint and basil essential oils: Chemical composition, in vitro antioxidant activity and in vivo estimation of skin irritation, J. Essent. Oil Bear. Plants. 5026 (2019) 1-15.

[78] E. Schmidt, S. Bailb, G. Buchbauerb, I. Stoilovac, T. Atanasovad, A. Stoyanovad, A. Krastanovc, L. Jirovetzb, Chemical composition, olfactory evaluation and antioxidant effects of essential oil from Mentha x piperita, Nat. Prod. Commun. 4 (2009) 1107-1112.

[79] P. Avato, F. Raffo, N.A. Aldouri, S.T. Vartanian, Essential oils of Varthemia iphionoides from Jordan, Flavour Fragr. J. 19 (2004) 559-561.

[80] K. Morteza-Semnani, Composition of the essential oil of Tanacetum polycephalum Schultz bip, J. Essent. Oil Res. 18 (2006) 129-130.

81] L. Salgueiro, R. Vila, X. Tomas, F. Tomi, S. Cañigueral, J. Casanova, A. Proença da Cunha, T. Adzet, Chemical polymorphism of the essential oil of Thymus carnosus from Portugal, Phytochemistry. 38 (1995) 391-396.

[82] N. Tabanca, N. Kirimer, B. Demirci, F. Demirci, K.H. Can Baser, Composition and antimicrobial activity of the essential oils of Micromeria cristata subsp. phrygia and the enantiomeric distribution of borneol, J. Agric. Food Chem. 49 (2001) 4300-4303.

[83] L. Tommasi, C. Negro, L. De Bellis, A. Miceli, Essential oil variability of Satureja cuneifolia ten. growing wild in southern Puglia (Italy), J. Essent. Oil Res. 20 (2008) 295-302

[84] M. Francisco, A. Arce, A. Soto, Ionic liquids on desulfurization of fuel oils, Fluid Phase Equilib. 294 (2010) 39-48.

[85] V.C. Srivastava, An evaluation of desulfurization technologies for sulfur removal from liquid fuels, RSC Adv. 2 (2012) 759-783.

[86] U. Domańska, M. Wlazło, M. Karpińska, [DCA]-based ionic liquids for the extraction of sulfur and nitrogen compounds from fuels: Activity coefficients at infinite dilution, Fluid Phase Equilib. 507 (2020) 1-12.

[87] M. Karpińska, M. Wlazło, Application of dicyanamide-based ionic liquid in separation of binary mixtures based on gamma infinity data measurements, J. Mol. Liq. 310 (2020).

[88] U. Domańska, K. Paduszyński, Gas-liquid chromatography measurements of activity coefficients at infinite dilution of various organic solutes and water in tri-isobutylmethylphosphonium tosylate ionic liquid, J. Chem. Thermodyn. 42 (2010) 707-711.

[89] M. Królikowska, M. Orawiec, Activity coefficients at infinite dilution of organic solutes and water in tributylethylphosphonium diethylphosphate using gas-liquid chromatography: Thermodynamic properties of mixtures containing ionic liquids, J. Chem. Eng. Data 61 (2016) 1793-1802.

[90] A.L. Revelli, L.M. Sprunger, J. Gibbs, W.E. Acree, G.A. Baker, F. Mutelet, Activity coefficients at infinite dilution of organic compounds in trihexyl(tetradeeyl)phosphonium bis(trifluoromethylsulfonyl)imide using inverse gas chromatography, J. Chem. Eng. Data 54 (2009) 977-985.

[91] N.R. Ronco, F. Menestrina, L.M. Romero, C.B. Castells, Determination of gas-liquid partition coefficients of several organic solutes in trihexyl(tetradecyl)phosphonium bromide using capillary gas chromatography columns, J. Chromatogr. A 1501 (2017) 134-141.

[92] A.L. Revelli, F. Mutetet, M. Turmine, R. Solimando, J.N. Jaubert, Activity coefficients at infinite dilution of organic compounds in 1-butyl-3-methylimidazolium tetrafluoroborate using inverse gas chromatography, J. Chem. Eng. Data 54 (2009) 90-101.

[93] U. Domańska, M. Laskowska, Measurements of activity coefficients at infinite dilution of aliphatic and aromatic hydrocarbons, alcohols, thiophene, tetrahydrofuran, MTBE, and water in ionic liquid [BMIM][SCN] using GLC, J. Chem. Thermodyn. 41 (2009) 645-650.

[94] U. Domańska, M. Wlazło, M. Karpińska, Activity coefficients at infinite dilution of organic solvents and water in 1-butyl-3-methylimidazolium dicyanamide. A literature review of hexane/hex-1-ene separation, Fluid Phase Equilib. 417 (2016) 50-61.

[95] E. Lukoshko, F. Mutelet, U. Domanska, Experimental and theoretically study of in teraction between organic compounds and tricyanomethanide based ionic liquids, J. Chem. Thermodyn. 85 (2015) 49-56.

[96] F. Mutelet, V. Butet, J.N. Jaubert, Application of inverse gas chromatography and regular solution theory for characterization of ionic liquids, Ind. Eng. Chem. Res. 44 (2005) 4120-4127.

[97] U. Domańska, M. Królikowski, Determination of activity coefficients at infinite dilution of 35 solutes in the ionic liquid, 1-butyl-3-methylimidazolium tosylate, using gas-liquid chromatography, J. Chem. Eng. Data 55 (2010) 4817-4822. 
[98] U. Domańska, A. Marciniak, Activity coefficients at infinite dilution measurements for organic solutes and water in the ionic liquid 1-butyl-3-methylimidazolium trifluoromethanesulfonate, J. Phys. Chem. B 112 (2008) 11100-11105.

[99] J.C. Moïse, F. Mutelet, J.N. Jaubert, L.M. Grubbs, W.E. Acree, G.A. Baker, Activity coefficients at infinite dilution of organic compounds in four new imidazolium-based ionic liquids, J. Chem. Eng. Data 56 (2011) 3106-3114.

[100] F. Mutelet, J.N. Jaubert, Accurate measurements of thermodynamic properties of solutes in ionic liquids using inverse gas chromatography, J. Chromatogr. A 1102 (2006) 256-267.

[101] J. Zhang, Q. Zhang, B. Qiao, Y. Deng, Solubilities of the gaseous and liquid solutes and their thermodynamics of solubilization in the novel room-temperature ionic liquids at infinite dilution by gas chromatography, J. Chem. Eng. Data 52 (2007) 2277-2283.

[102] T. Shida, Y. Hiraga, T. Sugiyama, Y. Sato, M. Watanabe, R.L. Smith, Measurement and modeling of infinite dilution activity coefficients of organic compounds in an equimolar ionic liquid mixture of [Bmim]cl and [Bmim] $\left[\mathrm{Tf}_{2} \mathrm{~N}\right]$, Fluid Phase Equilib. 488 (2019) 72-78.

[103] S. Sinnecker, A. Rajendran, A. Klamt, M. Diedenhofen, F. Neese, Calculation of solvent shifts on electronic g-tensors with the conductor-like screening model (COSMO) and its self-consistent generalization to real solvents (direct COSMORS), J. Phys. Chem. A 110 (2006) 2235-2245 